Check for updates

Cite this: Chem. Commun., 2017, 53, 12048

Received 10th September 2017, Accepted 12th October 2017

DOI: $10.1039 / c 7 c c 07083 g$

rsc.li/chemcomm

\section{Zirconium arene triple-decker sandwich complexes: synthesis, electronic structure and bonding $\dagger$}

\author{
A. F. R. Kilpatrick, (D) ${ }^{a}$ J. C. Green, ${ }^{b}$ Z. R. Turner, (D) ${ }^{a}$ J.-C. Buffet (D) and \\ D. O'Hare (D)*a
}

Reduction of a permethylpentalene zirconium(Iv) chloride complex $\left[\eta^{8}-\mathrm{Pn} * \mathrm{Zr}(\mu-\mathrm{Cl})_{3 / 2}\right]_{2}(\mu-\mathrm{Cl})_{2} \mathrm{Li} \cdot \mathrm{THF}_{x}$ with $\mathrm{KC}_{8}$ in benzene results in activation of the aromatic solvent to yield an "inverted sandwich" complex, $\left[\eta^{8}-\mathrm{Pn} * \mathrm{Zr}\right]_{2}\left(\mu-\eta^{6}: \eta^{6}-\mathrm{C}_{6} \mathrm{H}_{6}\right)$ (1). The reactions in toluene, cumene, 0 -xylene and $m$-xylene also yield analogous solvent activated triple-decker sandwich complexes, which have been structurally characterised by single-crystal X-ray diffraction. Edge energies in the Zr K-edge XANES spectra are not distinguishable between 1 and formally $\mathrm{Zr}(\mathrm{II})$ and $\mathrm{Zr}$ (Iv) reference compounds, suggesting a broad edge structure. DFT calculations best describe the bonding in 1 as highly covalent with frontier molecular orbitals showing almost equal contributions from benzene and the Zr-permethylpentalene fragments.

The bonding of benzene rings to a metal centre in an $\eta^{6}$-fashion has been known for over 60 years, ${ }^{1,2}$ and continues to be an area of intense research. ${ }^{3}$ Metal arene compounds are commonly synthesised by Fischer-Hafner chemical reduction of precursor complexes or by co-condensation of metal atoms with arenes at liquid nitrogen temperatures. ${ }^{4}$ The latter metal vapour synthesis (MVS) technique has led to the isolation of homoleptic bis( $\eta$-arene) complexes of the group 4 metals $\mathrm{Ti}^{5-7}$ $\mathrm{Zr}$ and $\mathrm{Hf}^{7}{ }^{7}$ in which the metal centre has a formal oxidation state of 0 . Compounds in which the arene bridges two metal centres symmetrically are referred to as "inverted sandwich" compounds. The first example for a group 4 metal was $\left[\mathrm{Hf}\left(\mathrm{PMe} \mathrm{PM}_{2}\right)_{2} \mathrm{I}_{2}\right]_{2}\left(\mu-\eta^{6}: \eta^{6}\right.$-arene $)$ synthesised by Cotton et al. via $\mathrm{Na} / \mathrm{Hg}$ reduction of $\mathrm{HfI}_{4}$ in the presence of $\mathrm{PMe}_{2} \mathrm{Ph}$ in benzene (or toluene). ${ }^{8}$ Quantum calculations on model system $\left[\mathrm{Zr}\left(\mathrm{PH}_{3}\right)_{2} \mathrm{I}_{2}\right]_{2}\left(\mu-\eta^{6}: \eta^{6}-\mathrm{C}_{6} \mathrm{H}_{6}\right)$ described the bonding in terms of arene frontier orbitals donating to and accepting from metal d orbitals.

\footnotetext{
${ }^{a}$ Chemistry Research Laboratory, Department of Chemistry, University of Oxford, 12 Mansfield Road, Oxford, OX1 3TA, UK. E-mail: dermot.ohare@chem.ox.ac.uk ${ }^{b}$ Inorganic Chemistry Laboratory, University of Oxford, South Parks Road, Oxford, OX1 3QR, UK

$\dagger$ Electronic supplementary information (ESI) available: Full experimental details and characterising data. CCDC 1573277-1573281. For ESI and crystallographic data in CIF or other electronic format see DOI: 10.1039/c7cc07083g
}

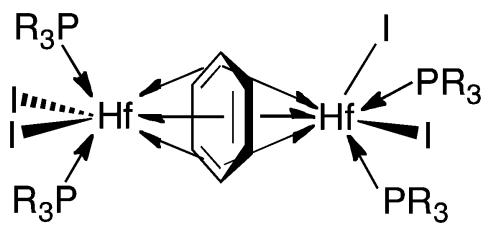

Fig. 1 Structure-bonding model of the first group 4 metal inverted sandwich complex. ${ }^{8}$

In a neutral electron counting system, arene ligands are also capable of serving as $\mathrm{L}_{3}$ donors to each metal centre, ${ }^{3,9}$ and a structure-bonding representation for the interaction is illustrated in Fig. 1. Thus, both hafnium centres of $\left[\mathrm{Hf}\left(\mathrm{PMe}_{2} \mathrm{Ph}\right)_{2} \mathrm{I}_{2}\right]_{2}\left(\mu-\eta^{6}: \eta^{6}\right.$-arene $)$ possess 16-electron configurations, with a formal oxidation state of +2. This was followed by a report in 1998 by Troyanov et al. for the analogous $\left[\mathrm{Hf}\left(\mathrm{PMe}_{3}\right)_{2} \mathrm{I}_{2}\right]_{2}\left(\mu-\eta^{6}: \eta^{6}-\mathrm{C}_{6} \mathrm{H}_{6}\right){ }^{10}$ The higher quality X-ray data for this complex compared with Cotton's original example enabled a detailed structural examination, which revealed a large deformation from planarity in the coordinated benzene ring. The observed 'twist-boat' geometry was attributed to steric repulsion between the benzene and the neighbouring $\mathrm{PMe}_{3}$ ligands. Since this discovery, a series of inverted sandwich compounds have been reported for the s-block ${ }^{11,12}$ d-block $^{13-18}$ and f-block ${ }^{19,20}$ elements. Most notably in the latter are the inverted sandwich complexes of uranium, ${ }^{21}$ for which there remains considerable debate regarding the $\mathrm{U}$ oxidation state.

The bicyclic pentalene ligand $\left(\mathrm{C}_{8} \mathrm{H}_{6}{ }^{2-}\right)$ shows an outstanding ability to stabilise complexes of reactive metal centres, ${ }^{22,23}$ particularly when coordinated in $\eta^{8}$-mode to an early transition metal or f-element. O'Hare and co-workers have developed the organometallic chemistry of permethylpentalene $\left(\mathrm{C}_{8} \mathrm{Me}_{6}{ }^{2-}, \mathrm{Pn}^{*}\right),{ }^{24}$ in particular that of the group 4 metals ( $\mathrm{Ti}, \mathrm{Zr}$ and $\mathrm{Hf}$ ) in the context of small molecule activation ${ }^{25}$ and ethylene polymerisation catalysis. ${ }^{26-28}$ Herein, we report the synthesis and characterisation of a series of triple-decker sandwich complexes of zirconium which feature the $\eta^{8}-\mathrm{Pn}^{*}$ ligand and a $\mu-\eta^{6}: \eta^{6}$-bridging arene.

The recent report of a series of " $\eta^{8}-\mathrm{Pn}^{*} \mathrm{MCl}_{2}$ " synthons provided a convenient entry point to these studies. ${ }^{29}$ Preliminary cyclic 


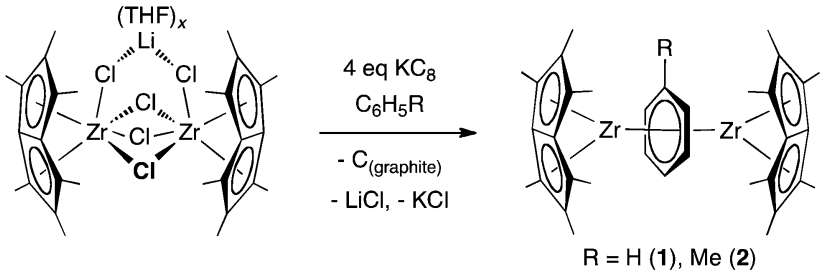

Scheme 1 Synthesis of inverted sandwich complexes of benzene (1) and toluene (2)

voltammetry (C.V.) studies on $\left[\eta^{8}-\mathrm{Pn}^{*} \mathrm{Zr}(\mu-\mathrm{Cl})_{3 / 2}\right]_{2}(\mu-\mathrm{Cl})_{2} \mathrm{Li} \cdot \mathrm{THF}_{x}$ in THF revealed an irreversible reduction event at $-2.63 \mathrm{~V}$ (Fig. S1, ESI $\dagger$ ), which prompted us to explore the reduction chemistry of this complex.

Addition of $\mathrm{KC}_{8}$ to a benzene solution of $\left[\eta^{8}-\mathrm{Pn}{ }^{*} \mathrm{Zr}(\mu-\mathrm{Cl})_{3 / 2}\right]_{2^{-}}$ $(\mu-\mathrm{Cl})_{2} \mathrm{Li} \cdot \mathrm{THF}_{x}$ resulted in a colour change in the solution from brown to red after $20 \mathrm{~h}$, with an accompanying grey/black precipitate. Following work-up and crystallisation, a benzene inverted sandwich complex $\left[\eta^{8}-\mathrm{Pn}{ }^{*} \mathrm{Zr}\right]_{2}\left(\mu-\eta^{6}: \eta^{6}-\mathrm{C}_{6} \mathrm{H}_{6}\right)$ (1) was isolated in $33 \%$ yield and identified by single-crystal X-ray diffraction (Scheme 1 and Fig. 2). The solid-state molecular structure reveals two $\mathrm{Zr}$ atoms symmetrically disposed either side of a bridging benzene ligand. The $\mathrm{Pn}^{*}$ ligands are twisted with respect to each other $\left(45.3(4)^{\circ}\right)$. The bridging benzene is non-planar as has been reported for $\left[\mathrm{Hf}\left(\mathrm{PR}_{3}\right)_{2} \mathrm{I}_{2}\right]_{2}\left(\mu-\eta^{6}: \eta^{6}\right.$-arene $)$

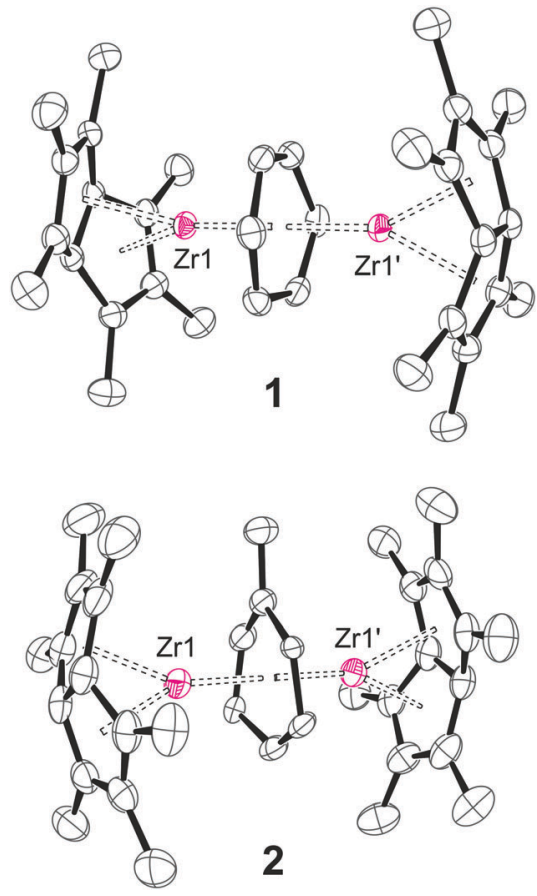

Fig. 2 Thermal displacement ellipsoid drawing (50\% probability) of 1 and 2. Hydrogen atoms are omitted for clarity. Selected interatomic distances $(\AA)$ ), angles $\left({ }^{\circ}\right)$ and structural parameters (defined in Fig. S22, ESI†): (for 1) Zr..Zr 3.8437(6), av. Zr-C arene 2.4013, av. C-C arene 1.4640(20), Puckering $Q_{\text {arene }} 0.226(4)$, Puckering $\phi_{\text {arene }} 330.0(10), \mathrm{Pn}^{*}$ twist angle $45.3, \mathrm{Pn}^{*}$ fold angle 33.1; (for 2) Zr...Zr 3.84765(12), av. Zr-C arene 2.4043, av. C-C arene $1.4680(17)$, Puckering $Q_{\text {arene }} 0.210(3)$, Puckering $\phi_{\text {arene }} 17.0(10), \mathrm{Pn}^{\star}$ twist angle 47.2, $\mathrm{Pn}^{*}$ fold angle 31.2 . complexes,${ }^{8,10}$ and the related diniobium-arene complexes. ${ }^{18}$ No crystallographic data have been reported for Kawaguchi's $\left[(\mathrm{ArO})_{2} \mathrm{Zr}\right]_{2}\left(\mu-\eta^{6}: \eta^{6}-\mathrm{C}_{6} \mathrm{H}_{5} \mathrm{R}\right)(\mathrm{R}=\mathrm{H}, \mathrm{Me})$ complexes, ${ }^{17}$ and there are no other arene-bridged dizirconium examples for structural comparison with 1.

${ }^{1} \mathrm{H}$ NMR spectroscopy of 1 in $\mathrm{C}_{6} \mathrm{D}_{6}$ at $298 \mathrm{~K}$ shows a spectrum consistent with $D_{2 \mathrm{~h}}$ molecular symmetry with resonances in $1: 2$ ratio assigned to the $\mathrm{Pn}^{*}$ wingtip and nonwingtip methyl groups respectively. A singlet at $2.82 \mathrm{ppm}$ is assigned to the equivalent protons of the coordinated benzene, a shift to lower frequency which has been attributed to shielding by the ancillary ligand set in analogous complexes. As expected, this resonance was absent in the ${ }^{1} \mathrm{H}$ NMR spectrum of the deuterated analogue 1- $d_{6}$ (prepared via $\mathrm{KC}_{8}$ reduction of $\left[\eta^{8}-\operatorname{Pn}{ }^{*} \mathrm{Zr}(\mu-\mathrm{Cl})_{3 / 2}\right]_{2}(\mu-\mathrm{Cl})_{2} \mathrm{Li}^{-} \cdot \mathrm{THF}_{x}$ in $\left.\mathrm{C}_{6} \mathrm{D}_{6}\right)$. However, the ${ }^{2} \mathrm{H}$ NMR spectrum of $1-d_{6}$ in $\mathrm{C}_{6} \mathrm{H}_{6}$ showed a resonance at 2.79 ppm (Fig. S4, ESI $\dagger$ ).

The ${ }^{13} \mathrm{C}\left\{{ }^{1} \mathrm{H}\right\}$-NMR spectrum of $\mathbf{1}$ was consistent with this solution structure at $298 \mathrm{~K}$, and a proton-coupled ${ }^{13} \mathrm{C}$ NMR experiment provided a ${ }^{1} J_{\mathrm{CH}}$ coupling constant of $175.3 \mathrm{~Hz}$ (Fig. S6, ESI $\dagger$ ), a value greater than the corresponding parameter for aromatic $\mathrm{sp}^{2}$ carbons $(160(1) \mathrm{Hz}$ ) as been observed in the related diniobium-arene complexes. ${ }^{18}$ Variable temperature ${ }^{1} \mathrm{H}$ NMR studies of $\mathbf{1}$ in $\mathrm{C}_{7} \mathrm{D}_{8}$ show the protons of the coordinated benzene remain equivalent in the range 298-178 K, however, below $248 \mathrm{~K}$ the non-wingtip $\mathrm{CH}_{3}$ resonance resolves into two singlets (Fig. S9, ESI $\dagger$ ). This is attributed to slower rotation of the two $\mathrm{Pn}^{*} \mathrm{Zr}$ fragments with respect to the arene centroid, which remains an inversion centre, rendering the molecule $D_{2}$ symmetric on the NMR timescale in the low temperature regime. The activation energy associated with this dynamic $\mathrm{Pn}^{*}$ twisting process at $285 \mathrm{~K}\left(\Delta G_{285 \mathrm{~K}}^{\ddagger}\right)$ was calculated by Eyring analysis as $56(3) \mathrm{kJ} \mathrm{mol}^{-1}$ (Fig. S10, ESI $\dagger$ ).

To investigate the effect of substituents on the structures and arene-zirconium bonding interactions these synthetic studies were extended to toluene, cumene, $o$ - and $m$-xylene derivatives. In each case, addition of $\mathrm{KC}_{8}$ to a mixture of $\left[\eta^{8}\right.$ $\left.\mathrm{Pn}^{*} \mathrm{Zr}(\mu-\mathrm{Cl})_{3 / 2}\right]_{2}(\mu-\mathrm{Cl})_{2} \mathrm{Li} \cdot \mathrm{THF}_{x}$ and the parent arene resulted in a red solution, which following filtration and concentration yielded red crystals of the respective $\left[\eta^{8}-\mathrm{Pn}^{*} \mathrm{Zr}\right]_{2}\left(\mu-\eta^{6}: \eta^{6}\right.$-arene $)$ complex, for arene $=\mathrm{C}_{6} \mathrm{H}_{5} \mathrm{Me}\left(2\right.$, Fig. 1), $\mathrm{C}_{6} \mathrm{H}_{5}{ }_{5}^{\mathrm{i}} \operatorname{Pr}(3), \mathrm{C}_{6} \mathrm{H}_{4}\left\{1,2-\mathrm{CH}_{3}\right\}_{2}$ (4) and $\mathrm{C}_{6} \mathrm{H}_{4}\left\{1,3-\mathrm{CH}_{3}\right\}_{2}$ (5). The molecular structures determined by single-crystal X-ray diffraction are shown in the ESI, $\dagger$ Fig. S17-S21, and selected metrical parameters are listed in Table S3 (see ESI $\dagger$ ), which reveal minimal variation between the series. The proposed formulations for $\mathbf{1}$ and $\mathbf{2}$ were confirmed by mass spectrometry and elemental analysis, however analytically pure samples of 3-5 could not be obtained due to the co-crystallisation of $\mathrm{Pn}_{2}^{*} \mathrm{Zr},{ }^{30}$ observed in the $\mathrm{KC}_{8}$ reduction of $o$-xylene and cumene as a minor product, and as a major product in the case of $m$-xylene.

NMR spectroscopic data for $\mathbf{2 - 5}$ in $\mathrm{C}_{6} \mathrm{D}_{6}$ indicate eclipsed $\mathrm{Pn}^{*}$ rings in each case and a fluxional $\mu$-arene ligand on the NMR timescale at $298 \mathrm{~K}$. For example the toluene ligand in 2 shows a second-order ${ }^{1} \mathrm{H}$ NMR spectrum with two multiplets at 2.58 and $3.13 \mathrm{ppm}$, assigned to the $o$ - $/ m$ - and $p$-ring protons 


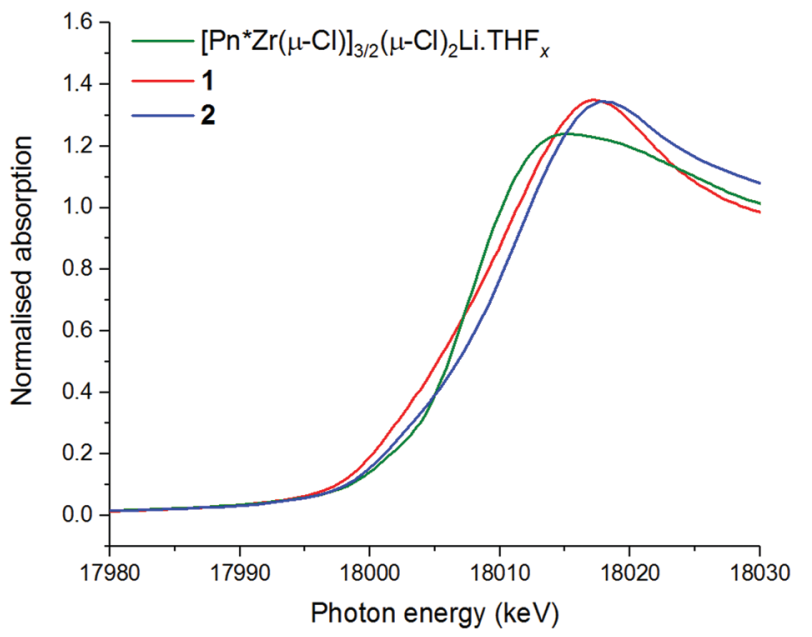

Fig. 3 Solid state XANES Zr K-edge spectra from 17980.0 to $18030.0 \mathrm{eV}$ of 1 and 2 along with $\left[\eta^{8}-\mathrm{Pn} \star \mathrm{Zr}(\mu-\mathrm{Cl})_{3 / 2}\right]_{2}(\mu-\mathrm{Cl})_{2} \mathrm{Li} \cdot \mathrm{THF}_{x}$ for comparison. The edge energy was determined from the maximum in the first derivative of the XANES spectrum (see ESI $\dagger$ ).

respectively, which can be simulated as a $\mathrm{AA}^{\prime} \mathrm{BB}^{\prime} \mathrm{X}$ spin system (Fig. S12, ESI $\dagger$ ).

${ }^{1} \mathrm{H}$ NMR spectroscopic studies showed that $\mathbf{1}$ and $\mathbf{2}$ do not undergo arene exchange reactions with toluene and benzene respectively at $373 \mathrm{~K}$ over 3 days. Furthermore, NMR-scale reactions in $\mathrm{C}_{6} \mathrm{D}_{6}$ reveal that complex 1 does not react with small molecules $\mathrm{H}_{2}, \mathrm{CO}, \mathrm{CO}_{2}, \mathrm{C}_{2} \mathrm{H}_{4}$ or azobenzene at room temperature, suggesting a degree of kinetic stability which is in stark contrast to the rich chemistry showed by other inverted sandwich complexes. ${ }^{4,14,16,17,21}$ Presumably, steric congestion around the metal centres prevent $\mathbf{1}$ from undergoing further reaction.

Zr K-edge XANES spectroscopic measurements were used to analyse the electronic structure and bonding in these complexes. Zirconocenes $\mathrm{Cp}^{\mathrm{R}}{ }_{2} \mathrm{Zr}(\mathrm{X})_{2} ; \mathrm{Cp}^{\mathrm{R}}=\mathrm{Cp}, \mathrm{Cp}^{*} ; \mathrm{X}=\mathrm{Cl}$, CO, together with known permethylpentalene $\operatorname{Zr}(\mathrm{Iv})$ complexes $\mathrm{Pn}^{*} \mathrm{ZrCpCl}$ and $\left[\eta^{8}-\mathrm{Pn}{ }^{*} \mathrm{Zr}(\mu-\mathrm{Cl})_{3 / 2}\right]_{2}(\mu-\mathrm{Cl})_{2} \mathrm{Li}^{-} \cdot \mathrm{THF}_{x}$ were studied as references. As anticipated, the low degree of $\mathrm{p}-\mathrm{d}$ mixing for $\mathrm{Zr}$, a $4 \mathrm{~d}$ transition metal, means that no pre-edge features were observed in the Zr XANES spectra for these complexes (Fig. 3). ${ }^{31}$ The edge energies were determined by the energy maxima in the $1^{\text {st }}$ derivative absorption spectra (Table 1). For the $\mathrm{Pn}^{*}$ and $\mathrm{Cp}^{\mathrm{R}}$ complexes these appeared as a broad shoulder at ca. $18.0 \mathrm{keV}$ in relatively low intensity, and in the case of

Table $1 \mathrm{Zr} \mathrm{K}$-edge energies of a series of $\mathrm{Cp}^{\mathrm{R}}$ and $\mathrm{Pn}^{*}$ zirconocene complexes

\begin{tabular}{ll}
\hline Compound & Edge energy $(\mathrm{eV})$ \\
\hline $\mathrm{Cp}_{2} \mathrm{Zr}(\mathrm{CO})_{2}$ & 18000.0 \\
$\mathrm{Cp}_{2}{ }_{2} \mathrm{Zr}(\mathrm{CO})_{2}$ & 17999.5 \\
$\mathrm{Cp}_{2} \mathrm{ZrCl}{ }_{2}$ & 18000.6 \\
$\mathrm{Cp}_{2}{ }_{2} \mathrm{ZrCl}{ }_{2}$ & 18000.7 \\
{$\left[\eta^{8}-\mathrm{Pn}^{*} \mathrm{Zr}(\mu-\mathrm{Cl})_{3 / 2}\right]_{2}(\mu-\mathrm{Cl})_{2} \mathrm{Li} \cdot \mathrm{THF}_{x}$} & 18001.6 \\
{$\left[\eta^{8}-\mathrm{Pn} \mathrm{Zr}_{2}\left(\mu-\eta^{6}: \eta^{6}-\mathrm{C}_{6} \mathrm{H}_{6}\right)(\mathbf{1})\right.$} & 18002.0 \\
{$\left[\eta^{8}-\mathrm{Pn}^{*} \mathrm{Zr}\right]_{2}\left(\mu-\eta^{6}: \eta^{6}-\mathrm{C}_{6} \mathrm{H}_{5} \mathrm{Me}\right)(2)$} & 18002.0
\end{tabular}

$\mathrm{Pn}^{*} \mathrm{ZrCpCl}$ the edge energy could not be definitively identified. The edge energy values are broadly similar for all the complexes studied and there is no significant shift for the formally $\operatorname{Zr}(\mathrm{II})$ dicarbonyls when compared with the more common $\operatorname{Zr}(\mathrm{Iv})$ complexes. Zr K-edge XANES studies of organozirconium complexes are scarce in the literature, however, a 2013 report by Williams et al. showed that benzene coordination to a surfacebound $\left[\mathrm{Cp}^{*} \mathrm{ZrMe}_{2}\right]^{+}$species results in a shift in the $\mathrm{Zr}$ K-edge to higher energy of $0.8 \mathrm{eV} .{ }^{32}$

Optimisation of the geometry of $\mathbf{1}$ at the BP86 level of theory (see ESI $\dagger$ ), and the unsubstituted model $[\mathrm{PnZr}]_{2}\left(\mathrm{C}_{6} \mathrm{H}_{6}\right)(\mathrm{I})$, gave structures with $D_{2}$ symmetry. $o$-Xylene and $m$-xylene complexes 4 and 5 and their respective models $[\mathrm{PnZr}]_{2}\left(\mu: \eta^{6}, \eta^{6}-\mathrm{C}_{6} \mathrm{H}_{4}\{1,2-\right.$ $\left.\left.\mathrm{CH}_{3}\right\}_{2}\right)(\mathbf{I V})$ and $[\mathrm{PnZr}]_{2}\left(\mu: \eta^{6}, \eta^{6}-\mathrm{C}_{6} \mathrm{H}_{4}\left\{1,3-\mathrm{CH}_{3}\right\}_{2}\right)$ (V) were optimised with no symmetry constraints and resulted in structures with effective $C_{2}$ symmetry. The toluene complexes 2 and II showed no symmetry. The cumene complexes $\mathbf{3}$ and III resulted in strongly differentiated pentalene ligands, more so for the model compound III than $\mathbf{3}$, presumably because of the closer proximity to the ${ }^{\mathrm{i}} \mathrm{Pr}$ group.

Key structural parameters calculated for $\mathbf{1}, \mathbf{I}, \mathbf{4}$ and $\mathbf{~ I V}$ are listed in Table S5 (see ESI $\dagger$ ), which reproduced the key features of the experimental structures of $\mathbf{1}$ and $\mathbf{4}$ quite closely. In all four cases the arene ring adopts a 'twist-boat' conformation ${ }^{33}$ with a Cremer-Pople puckering amplitude $(Q)^{34}$ of $c a .0 .25 \AA$ and the Pn rings are staggered by $c a .44^{\circ}$. Hence, DFT calculations suggest that both these structural features are electronic in origin and do not arise from the steric demand of $\mathrm{Pn}^{*}$ with respect to Pn, or indeed crystal packing forces.

A fragment calculation of $\mathbf{1}$ was carried out building the molecule from two $\left[\eta^{8}-\mathrm{Pn}{ }^{*} \mathrm{Zr}\right]$ units $^{30}$ and benzene. The results for key orbitals are shown in Fig. 4. Interaction between the $\mathrm{Zr}$ fragments and benzene involve the LUMOs of the benzene $\pi$ system, $\pi 4$ and $\pi 5$. In the $D_{2}$ symmetry of the molecule, these transform with $a$ and $b_{1}$ symmetry, hence they can only interact with the $\mathrm{ZrPn}^{*}$ orbitals of symmetry $a$. The $\mathrm{ZrPn}^{*}$ orbitals of symmetry $b$ give linear combinations of $b_{2}$ and $b_{3}$ symmetry. The orbitals $26 \mathrm{a}$ and $25 \mathrm{~b}_{1}$ which derive from $22 \mathrm{a}$ for $\mathrm{ZrPn}^{*}$ illustrate how the bonding orbitals of the pentalene unit are minimally perturbed by bonding to benzene. The $\mathrm{ZrPn}^{*}$ orbitals 23a and 24a hybridise to form combinations that overlap with $\pi 4$ and $\pi 5$ to form $27 \mathrm{a}$ and $26 \mathrm{~b}_{1}$ respectively. Inspection of the isosurface of 27 a shows how the pentalene rings have to be tilted with respect to each other so as to match the $\delta$ symmetry of the $\pi 4$ orbital. Occupancy of $27 \mathrm{a}$ and $26 \mathrm{~b}_{1}$ by four electrons originating from the $\mathrm{ZrPn}^{*}$ fragments represents donation into the antibonding orbitals of benzene and a charge shift from $\mathrm{Zr}$ to benzene. The bonding interaction is highly covalent with these orbitals showing almost equal contributions from benzene and the $\mathrm{ZrPn}^{*}$ fragments.

Fragment calculations were also carried out treating the zirconium-pentalene units and the arene as separate fragments. Consequent charges on the fragments, estimated by Hirshfeld partitioning method ${ }^{35}$ are given in Table S6 (see ESI $\dagger$ ). As might be anticipated introduction of alkyl groups on the arene ring in $\mathbf{2 - 5}$ and $\mathbf{~ I I - V}$ decreases the amount of charge transfer from 


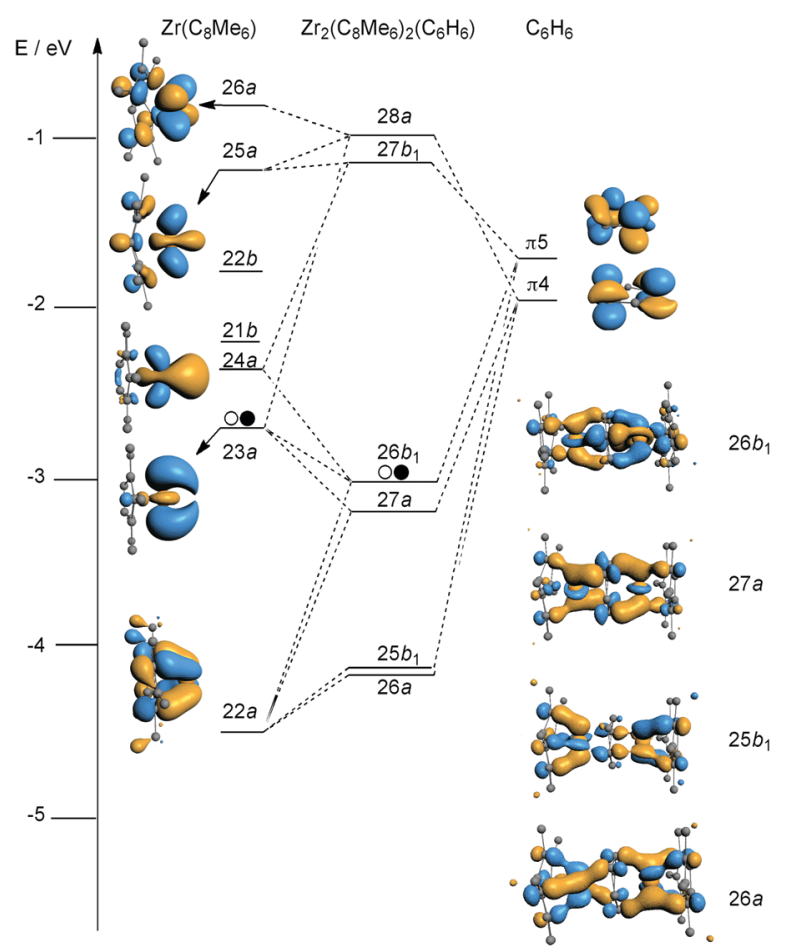

Fig. 4 Energy levels and isosurfaces for the Kohn-Sham frontier orbitals of 1 .

the zirconium-pentalene fragments compared with $\mathbf{1}$ and $\mathbf{I}$ respectively. However, comparison of the unsubstituted Pn structures with their respective $\mathrm{Pn}^{*}$ analogues shows a decrease in Hirshfeld charges and binding energies, which suggests, counter intuitively, that permethylation of pentalene decreases the donation from PnZr to the arene. This may be due to the steric demand of the six methyl groups preventing closer coordination of the arene to zirconium, reflected in the elongation (0.01 $\AA$ ) of $\mathrm{Zr}-\mathrm{Ar}_{\text {cent }}$ distances in $\mathbf{1}$ and $\mathbf{4}$ in comparison with $\mathbf{I}$ and IV respectively.

In conclusion we have synthesised a series of five dizirconium inverted sandwich complexes, which are the first examples of this class to be fully characterised by X-ray crystallography. The triple-decker compounds are kinetically stabilised with respect to arene-ligand exchange when dissolved in aromatic solvents, and are unreactive toward small molecules $\mathrm{H}_{2}, \mathrm{CO}$ and $\mathrm{CO}_{2}$. We have investigated their electronic structure using XANES spectroscopy and DFT calculations, which best describe the zirconiumarene bonding interactions as highly covalent.

AFRK, ZRT and J.-C. B thank SCG Chemicals Co., Ltd for funding. We thank the Diamond Light Source, UK. for the allocation of beam-time (sessions SP15521 and SP15150-1). We thank Dr G. Cibin and all the staff of Beamline B18 at the Diamond Light Source for assistance with the XANES measurements, and Prof. J. T. Miller for helpful discussions. Dr N. H. Rees (University of Oxford) is thanked for simulations of NMR spectra. AFRK also thanks Wadham College Oxford for a RJP Williams Junior Research Fellowship.

\section{Conflicts of interest}

There are no conflicts to declare.

\section{Notes and references}

1 E. O. Fischer and W. Hafner, Z. Naturforsch., B: Anorg. Chem., Org. Chem., 1955, 10, 665.

2 E. O. Fischer and W. Hafner, Z. Anorg. Allg. Chem., 1956, 286, 146-148.

3 V. Beck and D. O'Hare, J. Organomet. Chem., 2004, 689, 3920-3938.

4 G. Pampaloni, Coord. Chem. Rev., 2010, 254, 402-419.

5 M. T. Anthony, M. L. H. Green and D. Young, J. Chem. Soc., Dalton Trans., 1975, 1419-1422.

6 P. N. Hawker, E. P. Kündig and P. L. Timms, J. Chem. Soc., Chem. Commun., 1978, 730-731.

7 F. G. N. Cloke, M. F. Lappert, G. A. Lawless and A. C. Swain, J. Chem. Soc., Chem. Commun., 1987, 1667-1668.

8 F. A. Cotton, P. A. Kibala and W. A. Wojtczak, J. Am. Chem. Soc., 1991, 113, 1462-1463.

9 J. C. Green, M. L. H. Green and G. Parkin, Chem. Commun., 2012, 48, 11481-11503.

10 S. I. Troyanov, A. Meetsma and J. H. Teuben, Inorg. Chim. Acta, 1998, 271, 180-186.

11 A. Sekiguchi, K. Ebata, C. Kabuto and H. Sakurai, J. Am. Chem. Soc., 2002, 113, 7081-7082.

12 S. Krieck, H. Görls, L. Yu, M. Reiher and M. Westerhausen, J. Am. Chem. Soc., 2009, 131, 2977-2985.

13 G. B. Nikiforov, P. Crewdson, S. Gambarotta, I. Korobkov and P. H. M. Budzelaar, Organometallics, 2007, 26, 48-55.

14 Y.-C. Tsai, P.-Y. Wang, S.-A. Chen and J.-M. Chen, J. Am. Chem. Soc., 2007, 129, 8066-8067.

15 C. Ni, B. D. Ellis, J. C. Fettinger, G. J. Long and P. P. Power, Chem. Commun., 2008, 1014-1016.

16 Y.-C. Tsai, P.-Y. Wang, K.-M. Lin, S.-A. Chen and J.-M. Chen, Chem. Commun., 2008, 205-207.

17 T. Watanabe, Y. Ishida, T. Matsuo and H. Kawaguchi, Dalton Trans., 2010, 39, 484-491.

18 T. L. Gianetti, G. Nocton, S. G. Minasian, N. C. Tomson, A. L. D. Kilcoyne, S. A. Kozimor, D. K. Shuh, T. Tyliszczak, R. G. Bergman and J. Arnold, J. Am. Chem. Soc., 2013, 135, 3224-3236.

19 C. M. Kotyk, M. E. Fieser, C. T. Palumbo, J. W. Ziller, L. E. Darago, J. R. Long, F. Furche and W. J. Evans, Chem. Sci., 2015, 6, 7267-7273. 20 W. Huang and P. L. Diaconescu, Dalton Trans., 2015, 44, 15360-15371.

21 S. T. Liddle, Coord. Chem. Rev., 2015, 293, 211-227.

22 O. T. Summerscales and F. G. N. Cloke, Coord. Chem. Rev., 2006, 250, 1122-1140.

23 F. G. N. Cloke, J. C. Green, A. F. R. Kilpatrick and D. O'Hare, Coord. Chem. Rev., 2017, 344, 238-262.

24 A. E. Ashley, A. R. Cowley and D. O'Hare, Eur. J. Org. Chem., 2007, 2239-2242.

25 R. T. Cooper, F. M. Chadwick, A. E. Ashley and D. O'Hare, Chem. Commun., 2015, 51, 11856-11859.

26 F. M. Chadwick, R. T. Cooper, A. E. Ashley, J.-C. Buffet and D. M. O'Hare, Organometallics, 2014, 33, 3775-3785.

27 Z. R. Turner, J.-C. Buffet and D. O'Hare, Organometallics, 2014, 33, 3891-3903.

28 D. A. X. Fraser, Z. R. Turner, J.-C. Buffet and D. O'Hare, Organometallics, 2016, 35, 2664-2674.

29 R. T. Cooper, F. M. Chadwick, A. E. Ashley and D. O'Hare, Organometallics, 2013, 32, 2228-2233.

30 F. M. Chadwick, R. T. Cooper and D. O'Hare, Organometallics, 2016, 35, 2092-2100.

31 J. P. Krogman, J. R. Gallagher, G. Zhang, A. S. Hock, J. T. Miller and C. M. Thomas, Dalton Trans., 2014, 43, 13852-13857.

32 L. A. Williams, N. Guo, A. Motta, M. Delferro, I. L. Fragala, J. T. Miller and T. J. Marks, Proc. Natl. Acad. Sci. U. S. A., 2013, 110, 413-418.

33 J. C. A. Boeyens, J. Cryst. Mol. Struct., 1978, 8, 317-320.

34 D. Cremer and J. A. Pople, J. Am. Chem. Soc., 1975, 97, 1354-1358.

35 C. Fonseca Guerra, J. W. Handgraaf, E. J. Baerends and F. M. Bickelhaupt, J. Comput. Chem., 2003, 25, 189-210. 